\title{
EFEKTIFITAS PEMBELAJARAN UPANISAD DALAM MEMBENTUK SISWA YANG BERKARAKTER
}

\author{
Oleh \\ Ni Nyoman Perni
}

\begin{abstract}
ABSTRAK
Selain Belajar adalah hal yang paling penting dalam menciptakan karakter manusia. itu, era postmodernisme menyiratkan degradasi moralitas, sehingga perlu untuk mempelajari pembelajaran yang efektif untuk menumbuhkan karakter. Sebaliknya ada stigma yang mengatakan bahwa belajar telah gagal dalam melahirkan karakter manusia. Kitab Upanishad sebagai kesimpulan dari fakta Veda Samhita bahwa itu berisi berbagai pembelajaran yang sangat efektif dalam mengembangkan karakter siswa. Secara implisit menekankan pengalaman belajar. Siswa diminta untuk mengalami terlebih dahulu, sehingga mengandalkan pengalaman, kematangan siswa akan terbentuk dan sangat efektif untuk menumbuhkan karakter. Selain itu, belajar Upanishad menekankan proses penguatan dengan menjalankan ajaran prinsifel, yaitu Abhyasa, Brahmacari dan Shraddha. Pembelajaran berikutnya berkaitan dengan kemandirian juga digambarkan dalam Upanishad bahwa banyak siswa benar-benar memiliki kemandirian. Belajar melalui kecenderungan spiritual, diyakini oleh para guru Upanishad dapat menumbuhkan karakter dan dapat mengubah roh manusia (Manava) terhadap karakter ilahi (Madhava).
\end{abstract}

\section{Kata Kunci : Selain Belajar adalah hal yang paling penting dalam menciptakan karakter manusia.}

\begin{abstract}
Learning is the most important thing in creating a human character. Moreover, the era of postmodernism implies a degradation of morality, so it is necessary to study the effective learning in order to foster character. Instead there is a stigma that says that learning has failed in giving birth to the human character. Book of the Upanishads as the conclusion of the Veda Samhita fact that it contains a variety of learning highly effective in developing students' character. Implicitly emphasizes learning experience. Students are required to experience in advance, so relying on the experience, maturity of the students will be formed and it is very effective to grow the character. In addition, learning Upanishads emphasize a strengthening process by running prinsifel doctrine, namely Abhyasa, Brahmacari and Shraddha. The next learning with regard to self-reliance is also described in the Upanishads that many students really have independence. Learning through the spiritual tendency, is believed by the Upanishads teachers can foster character and can transform the human spirit(Manava) towards the divine character (Madhava).
\end{abstract}

Keywords : Learning is the most important thing in creating a human

Efektifitas Pembelajaran Upanisad Dalam

Membentuk Siswa Yang Berkarakter 


\section{PENDAHULUAN}

Pembelajaran yang berkualitas merupakan prinsip yang fundamental harus dikembangkan dunia pendidikan, jika menghendaki terciptanya manusia yang maju, beradab, bermoral, berkarakter dan sejenisnya. Berdasarkan pada hal itu, semua bangsa di dunia mengembangkan pembelajaran, dan berusaha melakukan penyempurnaan agar dapat mengejawantahkan kehendak tersebut secara faktual.Tidak ketinggalan pula bangsa Indonesia,telah melakukan berbagai pengkajian yang mendalam terkait dengan pendidikan khususnya pembelajaran dengan harapan mampu melahirkan manusia berkarakter. Manusia yang berkarakter dalam konteks ini dapat dilihat dalam rumusan UU Sistem Pendidikan Nasional No.20 Tahun 2003, sebagaimana yang dikutip Sukardjo (2012: 14), menyebutkan bahwasanya pendidikan nasional bertujuan untuk mengembangkan potensi peserta didik agar menjadi manusia yang beriman dan bertakwa kepada Tuhan Yang Maha Esa, berakhlak mulia, sehat, berilmu, cakap, kreatif, mandiri, dan menjadi warga Negara yang berdemokratis, serta bertanggung jawab.

Pengkajian yang mendalam danmendasarkan pada fakta yang sahih, para cendikiawan pendidikan di Indonesia telah mampu mereformulasi pembelajaran, kendatipun masihmengacu pada teori Barat.Pembelajaran yang bersandar pada teori Baratakan bertendensi sekulerisme, dan pembelajaran yang demikian kurang efektif membentuk peserta didik yang berkarakter.Secara emperikal pembelajaran yang bertendensi sekulerisme tidak akan dapat mengoptimalisasi perkembangan rohani peserta didik, karena peserta didik dituntut hanya menjadi pengkoleksi data, menghapal rumus, verbalisme-normatif, dan sejenisnya. Dengan kata lain, pembelajaran yang berkecendrungan sekulerimse hanya dapat mengasah kecerdasan intelektual (IQ) siswa.Secara elementer pembelajaran yang baik adalah pembelajaran yang mampu meyeimbangkan kecerdasan intelek, fisik, dan rohani siswa.Selain itu, tidak diejawantahkannya sistem pembelajaran secara maksimal, alih-alih ketidak profesionalan pendidik dalam pengaplikasian metode, sehingga berimplikasi pada terhambatnya pembelajaran.Oleh karena itu, banyak anomali paradigma yang menyebutkan pembelajaran telah gagal dalam mencapai tujuan yang ingin dicapai.Sebagaimana $\mathrm{Mu}$ 'in (2011: 21), dalam proksinya menjelaskan bahwa pembelajaran telah gagal; seyogyanya pembelajaran melahirkan manusia yang memiliki karakter mantap, justru sebaliknya melahirkan manusia yang berperilaku buruk.

Proksiyang menyebutkan bahwa pembelajaran telah gagal, kiranya dapat dibenarkan mengingat secara emperikal banyak masyarakat mengalami stagnasi moralitas, sehingga berdampak pada terdegradasinya moralitas bangsa.Tidak melakukan penampikan bahwa hal itu terjadi akibat dari diterapkannya pembelajaran yang tidak efektif.Banyak pendidikan melahirkan manusia dengan gelar tinggi, tetapi berperilaku tidak mencerminkan gelar yang dimiliki. Demikian pula, pembelajaran telah banyak melahirkan kaum intelektual, namun kering rohani. Kekeringan rohaniakan melahirkan manusia yang kosong dan tidak memiliki karakter. Selain itu, kekeringan rohani akan berimplikasi pada kecerdasan yang disfungsi.

Pembelajarandapatdikatakanefektifadalah pembelajaran yang mampu melahirkan siswa atau manusia yang berkarakter baik, bukan kecerdasan yang disfungsi, dan dalam pustaka suci Veda, tepatnya Upanisad hal tersebut sangat jelas digambarkan.Kitab Upanisad sendiri merupakan kitab bagian akhir atau kesimpulan dari kitab Veda.Meminjam uraian Radhakrishnan (2008: 8), bahwa Upanisad merupakan bagian penyimpulanVeda, dan kronologis Upanisad diturunkan pada akhir zaman Vedayang secara implisit menguraikan pembelajaran Veda.Senada dengan itu 
Mehta (2007: 45), menguraikan bahwa kitab Upanisad adalah risalah filosofis yang menguraikan pembelajaran Hindu, yang mana siswa diharapkan dapat memiliki pengetahuan rohani.Menilikpada hal itu, Upanisad merupakan kitab akhir dari Veda yang secara implisit menguraikan secara filsafati ajaran yang terkandung dalam Veda, dan dapat dijadikan tujuan pokoksekaligus arti dari ajaran Veda sekaligus gambaran indah sebuah pembelajaran berasaskan rohani.

Upanisad sendiri dapat diartikan duduk dekat guru untuk murid dapat mendengarkan ajaran dari guru suci.Upanisad sebagai sandaran dari Vedanta sangat banyak mengungkap pembelajaran yang efektif dalam mewujudkan siswa yang berkarakter. Diungkap dalam kitab Upanisad, para guru agung menerapkan pembelajaran sangat efektif, sehingga siswa atau sisyadapat memiliki karakter, dan dirinyamampu bertransformasimulai darimanava (manusia) menuju pada spirit madhava (karakter devata). Jadi, guru dalam pembelajaranUpanisad memiliki peran yang setrategis. Jabhala Satyakama, Svetakettu Aruneya, dan banyak lagi para siswa Upanisad yang dapat mewakili sebuah penggambaran siswa yang berkarakter, hasil dari suksesnya peran guru menerapkan pembelajaran berbasis pada pengalaman, penguatan dan kemandirian. Demikian juga guru suci, seperti Uddalaka, Gautama, Gargya,Janaka dan guru lainnya, sekian guru yang mewakili guru suci yang mampu menerapkan pembelajaran secara efektif, sehingga dapat menumbuh kembangkan karakter yang baik dalam diri siswa.Selain dari pada itu, guru berperan dalam memunculkan ekspresi rohani siswa dalam setiap kondisi.

Namun efektifitas pembelajaran yang terkandung dalam kitab Upanisad tidak banyak ada yang menggali dan menelaah untuk mereformulasi pembelajaran berbasis pada teks Veda, sehingga dapat diterapkan dalam kasanah pendidikan modern.Alihalih pendidikan Hindu, sangat jarang ditemukan pembelajaran yang murni berbasis Veda.Sedangkan dalam Veda banyak terdapat pembelajaran yang merefleksikan pembelajaran yang dapat menumbuhkan potensi peserta didik untuk menjadi berkarakter.Berdasarkan pada hal tersebut, teks kitab Upanisadakan dikaji, untuk menemukan pembelajaran yang relevan diaplikasikan dalam pembelajaran dewasa ini yang didasarkan pada rumusan masalah, sebagai berikut : 1) Bagaimana struktur ajaran dalam kitab Upanisad? 2) Bagaimana efektifitas metode pembelajaran Upanisad dalam menciptakan siswa yang berkarakter?

\section{PEMBAHASAN}

Disinggung sebelumnya bahwa Upanisad merupakan kesimpulan akhir dari $V e d a$, dan sebelum mendeskripsikan lebih jauh pembelajaran Upanisad, terlebih dahulu akan diuraikan sekilas tentang Upanisad. Kitab Upanisad sendiri secara harfiah dapat diterminologikan siswa atau sisya duduk dekat guru untuk mendengarkan ajaran suci (Radhakrishnan, 2008: 4).Merujuk pada kodefikasi Veda, kitab Upanisad merupakan kitab hasil dari pemikiran filosofis dalam universitas hutan (Aranyaka) yang kemunculannya diawali dari kitab Brahmana. Maka masing-masing kitab Brahmana memiliki puluhan kitab Upanisadyang merupakan bagian terpenting dari kitab Samhita Veda.Senada dengan itu, Mehta (2007: ix), menguraikan bahwa tendensi filosofis dari kitabSamhitadikembangkan dalam kitabUpanisad, dan Upanisad merupakan bagian penting dari kitab-kitab CaturVedaSamhita, seperti disebutkan bahwa kitab-kitab ini diyakini mampu melenyapkan kebodohan atau avidya sehingga tumbuh karakter yang baik dalam diri manusia. Dua belas Upanisad yang penting menurut Sivananda (2003: 17), adalah: (1) Isa, (2) Kena, (3) Katha, (4) Prasna, (5) Mundaka, (6) Mandukya, (7) Aitareya, (8)Taittiriya, (9) Chandogya, (10) Bahadaranya, (11) 
Kausitaki dan (12) SvetavastaraUpanisad. Kitab-kitab Upanisad memberikan wejangan tentang rahasia tertinggi kepada umat manusia. Wejangan ini disampaikan oleh guru rohani dengan baik kepada para muridnya dan merefleksikan pembelajaran yang menitikberatkan pada hal-hal yang rohani atau spiritual. Tidak saja menekankan pada rohani, tetapi aspek jasmani, material diperhatikan pula oleh para guru. KitabUpanisad sebagai nektar kitab Samhita Veda merupakan dasar dari segala pengetahuan bagi siswa, dan pengetahuan lain akan mengikuti. Berbagai kitab Upanisadmenjelaskan para guru rohani begitu baik dalam mentransfer pengetahuan kepada para siswa, dan mengaplikasikan pembelajaran yang efektif, di mana dalam guru memberikan pelajaran kepada para siswa dalam berbagai cabang pengetahuan manusia, guru sangat menekankan pada siswa bahwa pengetahuan belaka tidak akan berguna dan harus diilhami oleh kebijaksanaan. Para guru inimengusahakan agarnyala ilmu pengetahuan itu terus terpelihara, sehingga pembelajaran siswa tidak akan pernah berakhir.Untuk lebih jelasnya berikut akan diuraikan struktur ajaran dalam kitab Upanisad dan pembelajaran yang terkandung dalam kitab Upanisad.

\section{Struktur Ajaran Dalam Upanisad}

Sebelumnya telah diuraikan bahwa kitab Upanisad muncul dibagian akhir Aranyaka. Jika Samhitadiibaratkan sebuah pohon, kitab Brahmana adalah bunganya, Aranyaka adalah buahnya yang belum matang dan Upanisadadalah buah yang sudah matang (Saraswati, 2010 : 55). Menyimak analogi dari Sri Chandrasekarendra Sarasawati tersebut, dapat dipahami bahwa kitab Upanisad merupakan kitab akhir dari pengetahuan suci Vedayang menguraikan secara filosofis beragam konsep Tuhan, ritual dan etika. Hal itu senada dengan uraian Sivananda (2003: 16), kitab-kitab Upanisad merupakan bagian akhir dari Veda yang ajarannya berdasarkan pada kitab Upanisad disebut dengan Vedanta.Demikian pula,kitab-kitab Upanisadmerupakan intisari dari ajaran Veda yang membentuk pondasi dari ajaran Hindu, dan terkandung pemikiran filsafati berkenaan tentang Tuhan, ritual, etika dan kosmos. Merujuk pada urain tersebut, dapat ditemukan struktur ajaran di dalam kitab Upanisad, yaitu ajaran tentang ketuhanan, ritualistik dan etika

\section{Ajaran Ketuhanan}

Hampir secara keseluruhan kitab Upanisad memuat ajaran berkenaan dengan hakekat Tuhan. Tuhan dalam Upanisad disebut dengan Brahman, sebagaimana menurut Suamba (2003 : 260), Brahman diturunkan dari akar kata "brh" yang berarti tumbuh dan yang menyebabkan tumbuh atau hidup dari segala entitas hidup dan eksistensi. Oleh karena itu, dalam kitab Upanisad Tuhan dipandang menyusupi segalanya, sebagaimana Mahavakya (kalimat agung) dari Upanisad menyebutkan Sarvam Kaluidam Brahman (semuanya adalah Tuhan), demikian juga Tuhan menghidupi yang bergerak ataupun tidak (Isa Upanisad,I.1). Dalam kitab Chandogya Upanisad sangat jelas menyebutkan bahwa Tuhan adalah sari pati yang paling halus menghuni tubuh manusia dan memberikan kehidupan, sehingga muncul Mahavakya yang sangat terkenal, yaituTattvamasi.Secara implisit keseluruhan kitab Upanisad menjabarkan hakikat dari eksistensi yang tidak berbeda dengan Tuhan (Brahman), namun kekuatan maya dan avidya (kebodohan) yang mengkelirukan pandangan, sehingga seseorang tidak menyadari hakikat yang eksis dan non eksis.

Sesungguhnya Brahman atau Tuhanlah yang eksis dan nyata.Dalam Brhadaranyaka Upanisad hal itu sudah sangat tegas diuraikan, sebagaimana yang dikutip Radhakrishnan (2008:30), bahwa yang nyata dan pokok adalah Brahman sebagai san-matram hi brahma, yakni penyebab segalanya. Hal itu ditegaskan kembali dalam Brahma Sutra; Janmadyasya Yatah, artinya: Tuhan sumber segalanya. 
Adi Sankaracharya, pemberi sentuhan indah terhadap filsafat Advaita Vedanta dalam komentarnya tentang Chandogya Upanisad, sebagaimana dikutip oleh Ghambirananda Swami (2006: 15), menguraikan bahwa Brahman adalah yang Sat Cit Anandam, yakni keberadaan, pengetahuan dan kebahagiaan yang abadi. Senada dengan itu, menyitir uraian Zimmer (2003: 53),

\section{Ajaran Ritualistik}

Kitab Aranyaka mengawali kemunculan kitab Upanisad, dan secara harfiah Aranyaka dapat diterminologikan sebagai 'karya hutan' merupakan kelanjutan dari perkembangan jaman Brahmana yang memiliki ciri fundamental yang berbeda dari mantra dan brahmana. Karya hutan ini dibuat oleh orang yang sudah memasuki vanaprastha dan tidak lagi mampu melaksanakan kurban yajña.Para vanaprasthin tidak lagi terikat ritual, akan tetapi menemukan arti filosofis dari ritualistik. Ide ritualistik lama kelamaan semakin terpinggirkan dan yang muncul adalah ide bebas filosofis.Berdasarkan pada hal itu, Aranyaka merupakan awal dari Upanisad dan mengarahkan Upanisad untuk menggali nilai-nilai filsafat yang terkandung dalam kitab suci Veda.Namun kitab Upanisad tidak menegasikan ajaran ritualistik, tetapi terlebih pada memberikan penguatan filsafati tentang ritual. Dalam kitab Chandogya Upanisad misalnya, ada deskripsi singkat tentang upasana, ritual dan sejenisnya, akan tetapi tidak menekankan pada pemahaman ritualistik yang material sifatnya. Penyangkalan atau renunsiasi dengan jalan membatasi diri dari segala kesenangan dan menahan dahaga lapar, tiada lain merupakan prinsif hidup sebagai bentuk pengorbanan diri yang dapat menyucikan diri (diksah). Renunsiasi dapat dilakukan kapan saja, tanpa sarana upacara yang banyak, sehingga kitab Chāndogya Upanisadmengkonotasikanya sebagai bentuk dari upacara diksah.Radhakrisnan (2008 : 304), dalam uraiannya menjelaskan yajña ini adalah salah satu bentuk yajña yang utama.

Kehidupan adalah ritual dapat dimaknai sebagai bentuk persembahan, yakni mempersembahkan diri, kehidupan sepenuhnya kepada Tuhan, sebagaimana wacana Sathya Narayana (dalam Donder, 2006: 75), menguraikan bahwa mempersembahkan daun dapat dimaknai sebagai persembahan badan ini di atas daun itu, kemudian mempersembahkan bunga dapat dimaknai mempersembahkan pikiran di atas bunga itu, mempersembahkan buah dapat dimaknai mempersembahkan batin akan tapa rohani kepada Tuhan, dan mempersembahkan air dapat dimaknai sebagai persembahan air mata kebahagian karena Tuhan menciptakan semua yang ada ini.

\section{Ajaran Susila}

Susila secara harfiah berarti perilaku yang baik, dan susila sama pengertiannya dengan etika yang sama-sama merujuk pada perilaku yang sesuai dengan norma. Sesungguhnya dasar dari ajaran susila Hindu terdapat dalam Upanisad, karena dalam Upanisad menekankan pentingnya hidup dengan etika.Secara implisit ajaran susila dalam Upanisad mengarahkan manusia pada praktek kehidupan yang tanpa ego.Ego menurut para guru agung Upanisad, sebagaimana dikutip oleh Singh (2005: 117), merupakan asas yang menyebabkan segala penderitaan, maka ego harus dikelola dengan baik supaya tidak menutupi kesadaran. Setiap manusia memiliki ego, bukan berarti melakukan penegasian padanya, namun terlebih pada pengelolaan atau kontrol terhadap ego.Manusia sendiri sangat bertanggung jawab terhadap perbuatannya sendiri, dan kejahatan adalah kebebasan manusia dalam menggunakan kebebasannya untuk melayani indriawi yang membabi buta. Secara esensial, kitab Upanisad menguraikan bahwa Atman adalah bagian dari Brahman yang mengalir dalam segala entitas kehidupan, sehingga manusia adalah tidak berbeda, dan ini adalah landasan ajaran susila. 
Dibalik ragawi adalah Atman, dan semua bersaudara bersumber dari yang satu, sehingga melakukan kekerasan sama orang lain sama dengan melakukan tindakan kekerasan terhadap diri sendiri. Prinsif inilah yang mendasari konsep Aham Brahmaasmi (Saya adalah tuhan), Jadi, ajaran etika dalam Upanisad menekankan pada penyadaran akan hakikat bahwa ada unsur yang sama dibalik penampakan fenomenal, dan manusia bertanggung jawab terhadap perbuatannya sendiri, sebagaimana dalam kitab Brhadaranyaka Upanisad yang dikutip oleh Putra (2008: 173), menguraikan bahwa sesuai dengan perbuatannya demikianlah seseorang jadinya. Yang berbuat baik akan menjadi baik, yang berbuat jahat akan menjadi jahat, yang menjadi suci akan menjadi suci. Dari keinginan munculnya kehendak, dari kehendak munculnya tindakan dan dari tindakan muncul karma.Jadi, perbuatan baik dan buruk manusialah yang menentukan dan bertanggung jawab atas tindakannya.

\section{Pembelajaran Upanisad}

Mengacu padauraiannya Suprihatiningrum (2013: 75), pembelajaran adalah serangkaian kegiatan yang melibatkan pendidik dengan peserta didik dalam suatu lingkungan untuk memudahkan peserta didik atau siswa belajar. Lebih jauh diuraikan bahwa pembelajaran adalah proses yang utama yang diselenggarakan dalam kehidupan yang menggabungkan antara pekerjaan dan pengalaman. Meminjam uraian Sanjaya (2008: 102), bahwa pembelajaran adalah sebuah instruksi agar siswa dapat mempermudah dalam belajar, sehingga mendorong terjadinya perubahan dalam diri siswa, dan guru sebagai sumber belajar memegang peranan penting dalam proses pembelajaran. Merujuk pada terminologi tersebut, maka dapat dikatakan bahwa pembelajaran adalah sebuah proses yang melibatkan guru dengan siswa, dan guru sangat berperan penting dalam mempurmudah siswa belajar, sehingga mencapai tujuan dari pembelajaran. Merujuk pada terminologi itu pula, maka secara defenitif pembelajaran Upanisad adalah suatu proses yang melibatkan guru dengan siswa (sisya) dalam suatu lingkungan yang merupakan sintesa antara svadharma (kewajiban) dan pengalaman untuk siswa dapat bertransformasi. Demikian juga dalam proses, guru memegang peranan yang penting dalam upaya mempermudah siswa belajar agar dapat membangkitkan potensi siswa dengan menekankan pada pengalaman untuk menemukan, penguatan dan kemandirian. Berikut akan diuraikan pembelajaran yang terkandung dalam kitab Upanisad.

\section{Pembelajaran Berbasis Pengalaman}

Ditelaah secara mendalam, hampir secara keseluruhan kitab Upanisad menggambarkan akan sebuah pembelajaran yang menekankan pada mana siswa Upanisaduntuk dapat mengalami. Dalam siswa menerima pengetahuan dari guru, tidak serta merta siswa hanya menghafal apa yang ditransfer guru, akan tetapi terlebih pada mengalami..Mehta (2007: xi), dalam urainnya menyebutkan bahwa para guru Upanisad tidak menyuguhkan dan menerapkan sistem pembelajaran yang bersifat hafalan, dan guru tidak tidak akan pernah memberikan siswa pernyataan-pernyataan yang dibuat sistematis yang dapat siswa hafal. Akan tetapi, guru Upanisad akan menekankan pada siswa untuk mengalami, sehingga siswa dapat melakukan lompatan-lompatan kehidupan.

Guru memiliki peran sentral dalam pembelajaran Upanisad dan guru bergerak dari ide satu ke ide lain dengan menyerahkan langkah-langkah yang harus dialami untuk siswa memahami dan mampu menumbuhkan sisi spiritual dalam diri siswa. Disini guru mengarahkan agar siswa tidak hanya meniru sebuah gambar secara sempurna dari apa yang disampaikan guru, akan tetapi terlebih dahulu melakukan langkah-langkah itu, dan mengalami sendiri, sehingga siswa benar- 
benar memahami maksud guru. Hampir semuanya langkah-langkah tersebut bersandar pada pengetahuan rohani, sebab guru Upanisad memahami bahwa pengetahuan rohani adalah dasar dari segala pengetahuan di dunia. Semua guru dalam Upanisad secara eksplisit mengajarkan pengetahuan rohani berkenaan dengan Tuhan, hakikat sang diri, alam dan sejenisnya. Pembelajaran yang demikian, tidak berarti sebuah penggambaran ajaran yang disampaikan oleh guru bersifat esoteris, tetapi sengaja pengetahuan tersebut selalu dimunculkan sebab tujuan dari pembelajaran yang sebenarnya adalah siswa dapat memahami hakikat diri dalam hubungannya dengan Tuhan dan alam.

Pembelajaran yang demikian sangat jelas terlihat dalam kitab Chandogya Upanisaddan Upanisad lainnya, ketika Svetakettu diberikan pengetahuan oleh guru Uddalaka sekaligus ayahnya.Svetakettu diberikan pengetahuan tentang hakikat dari segala eksistensi, yakni adalah Atman sebagai saripati yang halus.Guru Uddalaka menyuruh Svetakettu untuk membawa garam dan air, dan setelah garam dilarutkan, guru Uddalaka menyuruh Svetakettu untuk mengalami langsung rasa garam dalam air dari berbagai posisi yang ternyata asin. Selanjutnya Uddalaka menyampaikan bahwa begitulah analoginya tentang eksistensi Tuhan yang dapat dirasakan, tetapi tidak diketahui rupanya, sehingga Tattvamasi Svetakettu,sebagaimana dalam petikan beberapa sloka berikut:

Lavanam etad udake'vadhaya, atha ma pratar upasidatha iti; sa ha tatha; hovaca: yad dosa lavanam udake' vadhah anga tad ahareti, tadd havamrsya na viv yatha vilinam, evam.

(Chandogya Upanisad, VI. 13.1)

Terjemahan :

Tempatkanlah garam ini pada air dan datanglah kepadaku besok pagi.Dia melakukan hal tersebut.kemudian beliau berkata kepadanya: "Garam itu yang kamu tempatkan kepada air kemarin malam, bawalah ke sini". Tentu saja dia tidak menemukannya sebab garam itu sudah larut (Radhakrishnan, 2008: 357).

Merujuk pada beberapa sloka tersebut terlihat dengan jelas bahwa guru dalam Upanisad dalam memberikan pengetahuan menekankan pada siswa untuk megalami, sehingga siswa lebih mudah memahami ajaran yang ditransfer oleh guru.Dalam sloka tersebut juga tergambarkan bahwa guru selalu memberikan pengetahuan rohani dan siswa dengan tunduk hati mendengarkan sekaligus mengikuti ucapan guru untuk pengetahuan itu dialami. Melalui pengalaman, siswa akan diarahkan pada penyadaran dan penemuan akan kebenaran dan akhirnya mencapai kematangan, sebagaimana menurut Zimmer (2003: 52), siswa Upanisad yang memiliki karakter adalah siswa yang merasakan sikap dengan pengalaman, sehingga memunculkan keyakinan (sradha) dan dengan itu siswa menemukan kebenaran serta kematangan. Kematangan dalam artian pendewasaan, dewasa dalam memaknai hidup, dewasa menjalani kehidupan ini, dan pembelajaran demikian jarang sekali ditemukan pada pembelajaran dewasa ini.Pembelajaran dewasa ini tidak secara concern menekankan untuk siswa mengalami pengetahuan rohani. Oleh sebab itu, pembelajaran yang diterapkan oleh guru tidak begitu efektif, alih-alih guru tidak memiliki kualifikasi khusus seperti guru Upanisad, sehingga pembelajaran hanya bersifat formalitas semata.

Pembelajaran Upanisad memperlihatkan peran guru yang sentral dalam mentransfer pengetahuan, dan guru memiliki kualifikasi yang baik dan professional. Guru tidak lagi membedakan deferenitas sosial, demikian juga para guru mengajar dengan penuh tanggung jawab, dan guru tidak akan berhenti memberikan pengetahuan sebelum siswa dirasa cukup untuk mengalami. Untuk siswa mau mengalami, terlebih dahulu guru 
memotivasi siswa untuk memiliki keinginan yang kuat (mumuksutva) untuk mengenal yang rohani.Hal tersebut terlihat jelas melalui pengalaman belajar siswa Upanisad bernama Jabhala Satyakama murid dari Rsi Gautama. Jabhala belajar kepada Gautama, dan sang guru memberikan motivasi untuk Jabahala memahami yang rohani hendaknya terlebih dahulu mengembalakan beberapa ekor sapi. Dalam mengembalakan sapi, Jabhala juga diharapkan melakukan tapas(sadhana spiritual, usaha yang keras)untukmendapatkan pelajaran dari alam, sehingga pada akhirnya mendapatkan pengalaman.

Tapassebagai laku sadhana adalah hal yang prinsif hendaknya dimiliki oleh siswa, dan siswa Upanisad semuanya memiliki kualifikasi tersebut.Siswa dalam mencari pengetahuan adalah tapas atau usaha yang keras, dan tidak adanya tapas tidak akan ada pengetahuan. Menyitir uraian Swami Ranganathanda (2000:16), siswa yang tidak memiliki prinsif tapas, maka akan susah mendapatkan pengetahuan, sebab tapas dan jnana adalah bersama-sama, artinya siswa yang melakukan tapas akan mendapatkan jnanas, sehingga mencapai kebijaksanaan dan mencapai penyucian. Hal tersebut ditegaskan dalam Bhagavadgita berikut:

Vita-raga-bhaya krodha mam-maya mam upasritah, Bahavo jnana-tapasa puta madbhavam agatah.

\section{(Bhagavadgita, IV.10)}

Terjemahan:

Terlepas dari hawa nafsu, rasa takut dan kemarahan, terserap dalam-Ku, berlindung kepada- $\mathrm{Ku}$, banyak orang tersucikan oleh laku tapa kebijaksanaan yang telah mencapai keberadaan-Ku (Maswinara, 1999: 234).

Tanpa tapas, siswa hanya duduk malas di dalam kelas, siswa tidak akan mendapatkan pengetahuan. Siswa harus membayarnya dengan usaha yang keras dan penuh perjuangan atau tapas.Banyak ditemukan dalam kitab Upanisad mengenai tapas, dan Sankaracharya mendefinisikan tapas sebagai; manasasca indriyanam ca aikagryam tapa ucyate (Kosentrasi energi pikiran dan organ indria dengan mengalami disebut tapas).. Pembelajaran Upanisad yang berbasis pada pengelaman tentunya dapat diaplikasikan, dan dalam hal ini guru lebih banyak memberikan siswanya untuk belajar kepada dirinya sendiri, alam lingkungan atau masyarakat, dan menekankan pada prinsif laku tapas (usaha yang keras)sehingga tercipta sebuah pola pengalaman dalam diri siswa. Pola pengalaman rohani secara tidak langsung akan dapat membentuk karakter siswa yang baik, kuat, spiritual dan tangguh. Seringnya siswa bersentuhan dengan pengalaman rohani, maka transformasi spirit manava menuju madhava akan terjadi dalam diri siswa.

\section{Pembelajaran Berbasis Penguatan}

Selain pembelajaran yang berbasis pengalaman, pembelajaran Upanisad juga memperlihatkan secara jelas pembelajaran yang menitik beratkan pada penguatan. Penguatan ini penting dimunculkan oleh guru Upanisad, karena guru Upanisad berpandangan bahwa kelemahan jiwa adalah sumber penderitaan.Hal tersebut sejalan dengan uraian Swami Vivekananda (dalam Kamajaya, 2006: 45), menyebutkan bahwa kelemahan adalah sumber penderitaan. Manusia mencuri, berbuat buruk, bertindak avidya (bodoh) dan sejenisnya adalah berawal dari kelemahan yang dimiliki manusia.Atas dasaritulah, guru dalam Upanisad memberikan penguatan kepada siswa sebagai syarat yang fundamental dimunculkan dari dalam diri siswa.Banyak ditemukan dalam Upanisad yang merefleksikan pembelajaran yang berbasis penguatan, dan untuk memunculkan penguatan dalam diri siswa, guru Upanisad menggunakan prosedur pembelajaran yang meliputi; Abhyasa, Bramacarya dan Sradha.

Abhyasa secara harfiah dapat diartikan 
sebagai pembiasaan, kebiasaan atau membiasakan.Untuk memberikan penguatan kepada siswa, guru Upanisad selalu memberikan pengulangan, sehingga siswa menjadi terbiasa sekaligus membiasakan diri untuk mendengar ucapan guru dan bisa mengaplikasikannya dalam tindakan. Pengualangan yang nampak jelas terlihat adalah ketikaguruakanmemulaipembelajaran, guru bersama siswa selalu mengucapkan doa, sehingga siswa dalam Upanisad menjadi terbiasa setiap mengerjakan apapun selalu berdoa,dan nampak keakraban guru dengan siswa sangat kuat. Doa dapat memberikan respon keheningan kepada siswa, sehingga transfer pengetahuan menjadi efektif. Dalam Kena Upanisad ada doa guru dengan murid sebagai berikut:

Semoga Brahman melindungi kami berdua. Semoga Brahman mengaruniakan kepada kami pahala pengetahuan.Semoga kami mendapatkan kekuatan guna meningkatkan pengetahuan.Semoga usaha belajar kami itu dapat mengungkapkan kebenaran. Semoga kami tidak saling menilai negatif satu sama lain (Mehta, 2007: 59).

Doa tersebut selalu diucapkan oleh guru Upanisad dan siswa bersama-sama agar mendapatan kekuatan untuk menambah pengetahuan. Demikian juga doa ini selalu diucapkan dengan pengulangan agar siswa terbiasa melakukan doa.Tentunya hal tersebut akan menanamkan kebiasaan yang baik dan penguatan akan terjadi dalam diri siswa. Abhyasa yang dilakukan guru diikuti dengan siswa bukanlah sesuatu yang buta, tetapi pembiasaan itu ditopang dan dipelihara oleh Jñana, yakni pengetahuan, Dhyana; fokus kepada Tuhan dan Tyaga, artinya iklas menerima kelebihan dan kekuarangan sebagai akibat dari karma, sehingga akan menemukan penguatan. Pembelajaran Upanisad sangat banyak menggambarkan untuk siswa memiliki penguatan dengan melakukan Abhayasa, membiasakan diri melakukan kebaikan, dan disiplin rohani yang mantap.
Selain Abhayasa, Brahmacari juga merupakan hal yang penting ditekankan kepada siswa.Brahmacari atau Brahmacaryamerupakan disiplin jasmani dan rohani dalam usaha pencapaian kelayakkan terhadap pengetahuan Veda (paravidya dan aparavidya).Meminjam uraian Sivananda (2003 : 57), tahapan pertama Brahmacaryamerupakan periode belajar dan disiplin. Brahmacari adalah fase sebelum memasuki tahapan Grehasta (berumah tangga).Pelajar atau siswahendaknya tidak memperturutkan kesenangan. Diketahui bahwasannya kesenangan akan menghambat siswadalam pembelajaran. Ajaran Brahmacari akan memberikan penguatan kepada siswa untuk siswa benar-benar terfokus belajar. Katha Upanisad menandaskan bahwa jalan kesenangan tidak akan membawa manusia atau siswa pada akhir. Sebagaimana menurut Putra (2010: 19), dalam Katha Upanisad menyebutkan bahwa ada dua jalan yang menarik manusia atau siswa untuk ada di dalamnya, yaitu jalan sreya (kebahagiaan) dan jalan preya (kesenangan). Jalan preya tidak akan sampai pada akhir, sedangkan jalan sreya akan membawa pada sebuah akhir, yaitu kebahagiaan. Melalui ajaran Barahmcari inilah gerak indria dikendalikan dengan baik untuk tidak memperturutkan kesenagan indria. Demikian pula, melalui Brahmacari, budhi sebagai alat pengendali indria dikuatkan. Katha Upanisad sangat indah menjelaskan hal tersebut melalui dialog antara Yama sebagai guru dari seorang siswa Brahmacari bernama Nachiketas. Dalam dialog tersebut, guru Yama berkata kepada siswa, bahwa budhi memiliki peranan penting dalam mengendalikan indria yang dianalogikan dengan kereta. Tubuh adalah kereta, indria adalah kudanya, pikiran adalah tali kekangnya, budhi adalah sikusir kereta dan jiva adalah penumpang kereta.Budhi sebagai kusir pengendali indria memiliki peranan penting dalam mengendalikan gerak kuda-kuda liar indria agar tidak menuju pada lembah jurang 
kehancuran.Oleh karena itu, budhi hendaknya dipertajam melalui ajaran pemurnian diri atau kebrahmacarian.Guru Upanisad selalu menjadikan konsep ini sebagai acuan dalam pembelajaran, agar siswa memiliki karakter dan terjadinya alur transformasi kesadaran dari manava (kesadaran manusia) menuju pada madhava (kesadaran dewata).Dalam artian, siswa selalu dapat memunculkan sisi kedewataan dalam perilaku.

Selain Brahmacari, ajaran tentang Sradaha sangat ditekankan dalam pembelajaran Upanisad, karena Sradha merupakan dasar untuk siswa menjalani kehidupan. Sradha hendaknya dimiliki siswauntuk siswa dapat berpikir tentang rasa kenyataan. Menurut Sankaracharya sebagaimana dikutip Radhakrisnan (2008 : 373), menguraikan tentang rasa kenyataan, yakni rasa dari ajaran agama. Siswadengan keyakinan yang dimilikinya akan mampu berpikir tentang pengetahuan yang ditransfer oleh guru. Tidak hanya berpikir, siswadengan keyakinan dan keimanannya akanmemperoleh ilmu pengetahuan dari gurunya. Hal ini dengan jelas diuraikan dalam sloka berikut :

Śradhāvāl labhate jñānam tat-parah samyatendriyah, Jñānam labdhvā pāram śāntim acirenādhighaccati.

\section{(Bhagavadgita, IV. 39)}

Terjemahan :

Ia yang memiliki keimanan yang mantap (sradha) memperoleh ilmu pengetahuan, menguasai panca indrianya, setelah memiliki ilmu pengetahuan dengan segera mencapai kedamaian yang abadi (Tim Penyusun, 2009 : 8).

Merujuk pada sloka di atas, menyiratkan bahwa keyakinan adalah sebagai syarat awal, jika siswaberkeinginan menyerap pengetahuan dari guru. Sebab dengan pengetahuan yang dimilikinya, siswasegera akan mencapai kesadaran akan Tuhan. Sejalan dengan hal tersebut, Singh (2005: 138), menguraikan bahwauntuk dapat menyadari kesadaran Tuhan, sradha sangat penting. Sradha bertujuan untuk membangunkan kesadaran akan Tuhan dalam diri manusia.

Dari ketidak yakinan ini akan berdampak pada terhambatnya proses pembelajaran dan pengetahuan yang disampaikan guru tidak meresap ke dalam ruang pemahaman siswa. Pengetahuan itu tidak akan dapat menyentuh sisi rohani siswa, jika pengetahuan itu tidak diyakini.Oleh karena itu, sradhamenjadi hal yang penting didalam menumbuhkan penguatan siswa, sehingga karakter akan terbentuk. Namun ajaran dalam Upanisad tersebut dewasa ini tidak benar-benar dapat diaplikasikan, sehingga siswa tidak bisa melakukan kebiasaan yang baik, memurnikan dirinya dan tidak tumbuhnya keyakinan dalam dirinya. Oleh karena itu, siswa dewasa ini menjadi lemah dalam segalanya, dan ini akan berimplikasi kepada terdistorsinya moralitas siswa. "Kelemahan adalah kematian dan kekuatan adalah kehidupan, olehnya jangan lemah, bangkit dan bangunlah", itulah yang sering diucapkan oleh Swami Vivekananda (dalam Kamajaya, 2001: 98), yang menyitir dari mahavakya dalam kitab Upanisad. Maka dari itu, sangat relevan pembelajaran Upanisad yang berbasis pada penguatan ini diaplikasikan dalam pendidikan modern, dan sebenarnya lebih banyak lagi ajaran dalam Upanisad yang secara implisit bertujuan untuk menguatkan jasmani dan rohani siswa.

\section{Pembelajaran Berbasis Kemandirian}

Membentuk peserta didik yang mandiri merupakan tujuan dari pembelajaran agar out put peserta didik benar-benar mampu dapat menghadapi dunia global. Hal tersebut tidak saja ditanamkan oleh pembelajaran modern, akan tetapi dari jaman terbentuknya sakha atau cabang dalam pembelajaran di universitas hutan atau Upanisad hal itu sudah diajarkan oleh guru kepada siswa. Harapan dari guru, agar siswa setelah menamatkan pembelajaran, 
keluar dari Gurukula (Ashram pada jaman Upanisad) dirasa sudah mampu memiliki kemandirian dan siap memasuki tahapan berikutnya.Pembelajaran yang berbasis pada kemandirian sangat banyak diuraikan dalam kitab Upanisad.Hampir secara keseluruhan guru suci dalam Upanisad mengejawantahkan pembelajaran yang mengarahkan untuk siswa mandiri dan tidak sepenuhnya tergantung kepada guru. Dalam Brhadaranyaka Upanisad akan dijumpai sosok guru yang cemerlang bernama Yajnavalkya, yang memberikan pembelajaran kepada Maharaja Janaka. Ketika raja Janaka merasa terpuaskan dengan ajaran guru Yajnavalkya, raja menawarkan harta yang berlimpah kepada guru.Namun guru dengan kerendahan hati menolak sambil mengatakan bahwa guru tidak berhak menerima apapun kecuali kalau guru sudah mengajarkan segala pengetahuan yang diketahui oleh guru.

Siswa sedapat mungkin diarahkan oleh guru untuk menyadari hakikat fundamental, bahwa dirinya sendirilah yang akan nantinya menentukan masa depan untuk siswa menjadi seperti yang dikehendaki. Guru hanya sebagai pemantik dari nyala api pengetahuan dan yang berhak menjaga itu adalah siswa. Siswa diajarkan selalu oleh guru untuk mandiri mengenali hakikat diri.Tidak saja demikian, guru juga memberikan pemahaman agar siswa dapat menerapkan pengetahuannya yang didapat dalam event kerja.Hal itu menandakan bahwa guru mengajarkan pola keseimbangan antara yang rohani dan jasmani. Guru Upanisad tidak menginginkan siswa Upanisad abu-abu dalam menjali kehidupan. Kemandirian dalam bingkai totalitas adalah sebuah objek studi yang harus diaplikasikan.

Isa Upanisad memberikan gambaran yang jelas berkenaan dengan hal tersebut.Sloka dari bait 9-14 secara maknawi mengajarkan siswa untuk tidak setengah-setengah. Bekerja tidak dengan pengetahuan akan sia-sia. Sebaliknya, memiliki pengetahuan tetapi tidak diterapkan dalam event kerja sama juga sia-sia belaka.
Siswa dalam pembelajaran Upanisad sangat dituntut mandiri dengan maksud untuk mengugah semangat berdikari, dan guru tidak semata-mata hanya menjejali pikiran siswa dengan hafalan rumus-rumus, data-data yang membingungkan. Tergugahnya semangat berdikari ini berarti pengembangan diri agar kepercayaan diri dapat tubuh. Siswa yang nantinya terjun dalam masyarakat diharapkan memiliki sikap percaya diri, dan selalu dapat menjaga api pengetahuan tidak pernah redup dalam dririnya.

Berbagai kitab Upanisad utama menjelaskan pembelajaran tersebut, pembelajaran yang mengarahkan kemandirian siswa.Sebut saja Jabhala Satyakama siswa Gautma.Jabhala diarahkan sepenuhnya untuk mandiri belajar kepada banyak guru, sehingga benar-benar menemukan pengetahuan melalui alam.Demikian juga Svetakettu Aruneya murid dari guru Uddalaka.Svetakettu selalu dibimbing dengan santun oleh guru untuk menemukan sendiri jawaban dari segala pertanyaan terkait tentang hakikat eksistensi. Tidak ketinggalan pula, Nachiketas siswa guru Yama selalu dituntun untuk sendiri menemukan jawaban segala pertanyaan itu melalui pengalaman, dan guru hanya sebagai fasilitator.

\section{SIMPULAN}

Kitab Upanisad merupakan akhir dari kesimpulan kitab Samhita Veda.Upanisad sendiri dapat diartikan duduk dekat guru untuk siswa mendengarkan ajaran yang suci.Merujuk pada kodefikasi Veda, kitab Upanisad merupakan kitab hasil dari pemikiran filosofis dalam universitas hutan (Aranyaka) yang kemunculannya diawali dari kitab Brahmana.Maka masing-masing kitab Brahmana memiliki puluhan kitab Upanisad yang merupakan bagian terpenting dari kitab Samhita Veda dan ajaran yang terkandung di dalamnya meliputi ajaran ketuhanan, ritual dan etika.Ajaran ketuhanan dalam Upanisad 
menempatkan Tuhan sebagai yang menyusupi segalanya, sumber segalanya, memberikan kehdiupan dan secara defenitif Tuha itu adalah Sat-Cit-Anandam.Ajaran ritualistik dalam Upanisad terlebih pada pemaknaan secara tendensius filosofis berkenaan dengan ritual.Hidup adalah lambang dari ritual, dan penyangkalan diri adalah dasar elementer. Penyangkalan diri adalah yajna yang utama sifatnya. Ajaran etika dalam Upanisad menyiratkan pemaknaan yang dalam akan hakikat eksistensi yang sma dibalik penampakan fenomenal. Hal itu terajut dalam Mahavakya Upanisad, yakni Tattvamasi, Aham Barahmasmi, Sarvam Kaluidam Brahman dan yang lainnya.

Efektifitas Pembelajaran Upanisad sangat jelas terdapat dalam berbagai kitab Upanisad utama. Pembelajaran berbasis pada pengalaman menitik beratkan pada peran guru untuk tidak menyuguhkan dan menerapkan sistem pembelajaran yang bersifat hafalan, tetapi guru Upanisad akan menekankan pada siswa untuk mengalami, sehingga siswa dapat melakukan lompatanlompatan kehidupan. Guru memiliki peran sentral dalam pembelajaran Upanisad dan guru bergerak dari ide satu ke ide lain dengan menyerahkan langkah-langkah yang harus dialami untuk siswa memahami dan mampu menumbuhkan sisi spiritual dalam diri siswa. Disini guru mengarahkan agar siswa tidak hanya meniru sebuah gambar secara sempurna dari apa yang disampaikan guru, akan tetpi terlebih dahulu melakukan langkah-langkah itu, dan mengalami sendiri, sehingga melalui pegalaman karakter siswa akan terbentuk. Pembelajaran berbasis pada penguatan merupakan pembelajaran yang menekankan pada peran serta guru dalam memberikan penguatan melalui pembelajaran yang bertumpu pada ajaran Abhyasa, Brahmacari dan Sradha.Melalui Abhyasa(membiasakan diri bersentuhan dengan rohani), siswa diharapkan mampu untuk dapat memurnikan dirinya, sehingga menjadi siswa yang mampu menghadapi distraksi yang muncul dari dalam maupun dari dalam diri siswa.. Sedangkan Sradha adalah yang fundamental untuk siswa dapat meyakini akan pengetahuan yang didapat untuk menguatkan diri. Dalam kitab Upanisad hal tersebut sangat banyak dijelaskan.Pembelajaran berlatar belakang mandiri, sehingga siswa mampu sendiri menemukan hakikat diri dan mengaplikasikan dalam kehidupan, dan peran guru hanya menjadi perantara.

\section{DAFTAR PUSTAKA}

Donder, I Ketut. 2006.Sisya Sista (Pedoman Menjadi Siswa Mulia, Religiopsikososioedukatif).Surabaya : Paramita.

Gambhirananda, Swami. 2006. Chandogya Upanisad, the Comentary Sankaracharya. Kolkata India:Advaita Ashrama, Mayavati, Champawat, Uttaranchal.

Kamajaya, I Gede dan Oka Sanjaya, I Gede. 2001. Svami Vivekananda-Vedanta Gema Kebebasan (Vedanta :Voice Of Freedom). Surabaya : Paramita.

Maswinara, I Wayan. 1999.Bhagavad Gita. Surabaya : Paramita.

Mu'in, Fatchul. 2011. Pendidikan Karakter Kontruksi Teoritik dan Praktik. Jogjakarta : Az-Ruzz Media.

Mehta, Rohit. 2007. Menemukan Tuhan Dalam Diri.Terjemahan Tjok Rai Sudharta. The Call Of Upanisad. 1970. Denpasar : Sarad. 
Putra, Ngakan Putu. 2008. Tuhan Upanisad Menyelamtkan Umat Manusia. Jakarta : Media Hindu.

..........,2010. Upanisad Himalaya Jiwa. Jakarta: Media Hindu.

Radhakrisnan, Sarvepali. 2008. UpanisadUpanisad Utama. Surabaya : Paramita.

Surabaya : Paramita.

Sandika, I Ketut.2013.Berjalan Pada Jejak Vedanta (Membangun Kekuatan Meningkatkan Kesadaran).Surabaya : Paramita.

Sanjaya, Wina. 2008. Kurikulum dan Pembelajaran. Jakarta : Kencana Prenada Media Group.

Saraswati, Sri Chandrasekharendra. 2010. Peta Jalan Veda.Jakarta : Media Hindu.

Singh, Ranvir. 2005. Veda Abad 21. Surabaya : Paramita.

Sivananda, Sri Svami. 2003.Intisari Ajaran Hindu. Surabaya : Paramita.

Suamba, I.B Putu. 2003. Dasar-Dasar Filsafat India. Denpasar: Widya Dharma.

Sukardjo, Komarudin. 2012. Landasan Pendidikan Konsep dan Aplikasinya. Jakarta : Rajawali Prees.

Suprihatiningrum . 2013. Setrategi Pembelajaran. Jojakarta : Ar-Ruzz Media.

Swami Ranganathananda. 2000. Bhagavadgita, Pesan Universal. Jakarta : Media Hindu.

Zimmer, Heinrich. 2003. Sejarah Filsafat India.Yogyakarta : Pustaka Pelajar. 